\title{
The investigation of salvage endoscopic laryngopharyngeal surgery after chemoradiotherapy
}

\author{
Yohei Kawasaki ${ }^{1}$, Yasufumi Omori ${ }^{2}$, Hidekazu Saito ${ }^{1}$, Shinsuke Suzuki ${ }^{1}$, Takechiyo Yamada $^{1}$ \\ ${ }^{1}$ Department of Otorhinolaryngology and Head and Neck Surgery, Graduate School of Medicine, Akita University, Akita, Japan \\ ${ }^{2}$ Department of Molecular and Tumor Pathology, Graduate School of Medicine, Akita University, Akita, Japan
}

Videosurgery Miniinv 2020; 15 (3): 511-518

DOI: https://doi.org/10.5114/wiitm.2020.94518

\begin{abstract}
Introduction: Endoscopic laryngopharyngeal surgery (ELPS) is an effective treatment for early-stage oropharyngeal and hypopharyngeal cancers. Since 2007, we have performed ELPS on 14 patients with early-stage cancer who had undergone radiation therapy (salvage ELPS). We discuss the beneficial effects and issues with salvage ELPS compared with those of fresh patients since we experienced some severe complications, such as ruptured pseudoaneurysm with salvage ELPS.

Aim: To our knowledge, the efficacy and safety of ELPS following radiation therapy have not yet been evaluated, and several unknown factors exist. An evaluation was performed for assessing whether ELPS following radiation therapy is safe, similar to findings in fresh cases previously reported by us, and whether this treatment method can be efficacious. Material and methods: We studied the cases of 14 patients who had undergone salvage ELPS after radiation therapy for head and neck cancer at Akita University Hospital between 2007 and 2018.

Results: The rate of recurrence of head and neck cancer at different sites after salvage ELPS was $48.9 \%$ at 2 years. Furthermore, deformation of the pharyngolarynx made it extremely difficult to perform surgery. We also experienced extremely severe complications of ruptured pseudoaneurysms.

Conclusions: If salvage ELPS is performed after radiation therapy, patients should be followed up on an outpatient basis to monitor the onset of subsequent cancers. Complications may become severe; therefore, postoperative management should be performed cautiously. In particular, vulnerable sites, such as the piriform sinus, may not be indicated for surgery. At this stage, the expectation is that patients need to be methodically selected.
\end{abstract}

Key words: salvage endoscopic laryngopharyngeal surgery, chemoradiotherapy, pseudoaneurysm.

\section{Introduction}

Endoscopic laryngopharyngeal surgery (ELPS) is an extremely effective treatment method for early-stage oropharyngeal and hypopharyngeal cancer [1-7]. At Akita University, the procedure had been performed jointly with the Department of Gastrointestinal Medicine since 2007 and, since 2015, has been performed independently by the Department of Otolaryngology [8]. To date, 81 oropharyngeal and hypopharyngeal cancer lesions have been treated with ELPS; however, in recent years, the onset of oropharyngeal and hypopharyngeal cancer within the irradiation field following chemoradiation therapy has increased. This may be largely attributed to the increased accuracy of endoscopy and improvements in positioning during observation [9].

\section{Address for correspondence}

Yasufumi Omori, Department of Molecular and Tumor Pathology, Graduate School of Medicine, Akita University, 1-1-1 Hondo, Akita,

010-8543 Japan, phone: +81 18-884-6059, fax: +81 18-836-2601, e-mail: yasu@med.akita-u.ac.jp 


\section{Aim}

Although ELPS following chemoradiation therapy (salvage ELPS) is expected to be a minimally invasive treatment method, the efficacy and safety of the procedure remain unclear. An evaluation of the efficacy and safety in patients undergoing salvage ELPS after chemoradiation therapy at our institution was performed.

\section{Material and methods}

The present study included 14 cases of patients with a prior history of chemoradiation therapy for head and neck cancer who had undergone salvage ELPS at our institution between 2007 and 2018. In all patients, the tumor could not be detected by methods such as computed tomography (CT) or magnetic resonance imaging (MRI) but was believed to be confined within the submucosa, and all patients strongly wished to undergo salvage ELPS. The target population also included patients who underwent salvage ELPS after squamous cell carcinoma was confirmed on the basis of biopsies performed under general anesthesia when performing biopsies on an outpatient basis was considered difficult.

The surgical procedure was performed as per normal ELPS, wherein the pharynx was expanded using Sato's curved laryngoscope (Nagashima Medical Instruments Co., Ltd, Tokyo, Japan) and the lesion was viewed using a 5-mm flexible scope, the EndoEye (Olympus Medical System Corp., Tokyo, Japan), and, while injecting saline containing epinephrine into the mucosa, lesions were surgically excised using FlushKnife (FUJIFILM, Kanagawa, Japan). Negative surgical margins were confirmed via rapid intraoperative diagnoses, and surgery was completed. Thereafter, the presence or absence of tumor in the margins was verified in permanent specimens. The probability of repeat surgery following ELPS or salvage ELPS was also evaluated.

We obtained informed consent from all patients before their enrollment in this study. This study was reviewed and approved by the Research Ethics Committee of Akita University Hospital and was conducted in accordance with the Declaration of Helsinki.

\section{Results}

All patients in the present study were male, and the mean age of the patients was 64.7 years. The total dose of radiation was 40 Gy in 2 patients, 66 Gy in 6 patients, and 70 Gy in 1 patient. The concomitant anticancer agents used were docetaxel (TXT) $\left(10 \mathrm{mg} / \mathrm{m}^{2} /\right.$ week $)$ in 6 patients, 2 courses of docetaxel, cisplatin and fluorouracil (TPF) in 1 patient, 3 courses of cisplatin (CDDP) $\left(100 \mathrm{mg} / \mathrm{m}^{2}\right)$ in 1 patient, and 4 courses of carboplatin (CBDCA) (at a dose of $75 \mathrm{mg} / \mathrm{m}^{2}$ (on day 1)) with 5-FU (at a dose of $250 \mathrm{mg}$ (on days 3 and 5)) administered via intra-arterial injection via the superficial temporal artery in 1 patient. One patient received treatment for nasopharyngeal cancer at a different institution and, therefore, the details are unknown. The time from chemoradiation therapy until the onset of head and neck cancer ranged from 6 months to over 10 years (Table I). The lesion sites included the superior oropharyngeal wall in 1 patient, the anterior oropharyngeal wall in 2 patients, the lateral oropharyngeal wall in 3 patients, the posterior oropharyngeal wall in 3 patients, the hypopharyngeal arytenoid cleft in 1 patient, the hypopharyngeal pyriform sinus in 1 patient, the posterior hypopharyngeal wall in 2 patients, and the posterior cricoid region in 1 patient. In all patients, negative surgical margins were confirmed by a pathologist on the basis of rapid intraoperative diagnoses and from permanent specimens (Table II). Consequently, in all patients, the morphology could be preserved, and major surgery requiring reconstruction could be avoided. Overall, the rate of local control was extremely good at $96.3 \%$ (Figure 1). We evaluated the probability of finding new lesions and of repeat surgery following ELPS; consequently, for fresh patients, the probability at 2 years was $16.4 \%$, whereas with salvage ELPS, the corresponding rate reached $48.9 \%$ (Figure 2). Although the observation period was short and the future course remains unclear with salvage EPS, compared with fresh patients, the probability of repeat surgery tended to be very high. These results suggest that, even if local control is achieved, there is an extremely high possibility of cancer lurking at different sites.

Even for lesions confined within the mucosa and for which the area of excision is not wide, severe complications can occur depending on the site. We surgically excised recurrent lesions in the hypopharyngeal piriform sinus using salvage ELPS. An explanation that in the future, normal oral intake would become difficult and that there would be a need to consume foods that would not be hard 
Table I. Summary of patient characteristics. The radiation dose was 40 Gy in 2 patients, 66 Gy in 6 patients, and 70 Gy in 1 patient. The anticancer agents used were TXT in 6 patients, TPF in 1 patient, CDDP in 1 patient, and intra-arterial injection via the superficial temporal artery of CBDCA + 5FU in 1 patient. The time to onset of head and neck cancer after chemoradiotherapy ranged from 6 months to over 10 years

\begin{tabular}{|c|c|c|c|c|c|c|}
\hline Patient & Sex & Age & $\begin{array}{l}\text { Total } \\
\text { dose } \\
{[G y]}\end{array}$ & Anticancer agent used & Prior surgical history & $\begin{array}{l}\text { Time to onset of } \\
\text { head and neck } \\
\text { cancer [months] }\end{array}$ \\
\hline $\begin{array}{l}\text { 1. Posterior hypopha- } \\
\text { ryngeal wall cancer } \\
\text { (T2N2cM0), stage IV }\end{array}$ & M & 64 & 66 & TXT 10 mg/m²/week & $\begin{array}{l}\text { Pharyngolaryngectomy, bilat- } \\
\text { eral cervical dissection, and } \\
\text { pectoralis major myocutane- } \\
\text { ous flap reconstruction }\end{array}$ & 29 \\
\hline $\begin{array}{l}\text { 2. Anterior oropha- } \\
\text { ryngeal wall cancer } \\
\text { (T2NOMO), stage II }\end{array}$ & M & 63 & 66 & TXT 10 mg/m²/week & $\begin{array}{l}\text { Total glossectomy, total lar- } \\
\text { yngectomy, bilateral cervical } \\
\text { dissection, and pectoralis } \\
\text { major myocutaneous flap } \\
\text { reconstruction }\end{array}$ & 120 \\
\hline $\begin{array}{l}\text { 3. Laryngeal cancer } \\
\text { (T4N2cM0), stage IV }\end{array}$ & M & 63 & 40 & TXT 10 mg/m²/week & $\begin{array}{l}\text { Total laryngectomy, bilater- } \\
\text { al cervical dissection, total } \\
\text { esophagectomy, and gastric } \\
\text { tube reconstruction }\end{array}$ & 74 \\
\hline \multirow{2}{*}{$\begin{array}{l}\text { 4. Posterior hypopha- } \\
\text { ryngeal wall cancer } \\
\text { (T3NOMO), stage III }\end{array}$} & M & 78 & 66 & $\begin{array}{l}5 F U\left(600 \mathrm{mg} / \mathrm{m}^{2}\right. \\
\text { day } 1-5)\end{array}$ & \multirow[t]{2}{*}{ Tracheostomy } & \multirow[t]{2}{*}{8} \\
\hline & & & & $\begin{array}{l}\text { TXT }\left(50 \mathrm{mg} / \mathrm{m}^{2} \text {, day } 1\right), \\
\operatorname{CDDP}\left(60 \mathrm{mg} / \mathrm{m}^{2} \text {, day } 4\right) \\
2 \text { courses }\end{array}$ & & \\
\hline $\begin{array}{l}\text { 5. Posterior hypopha- } \\
\text { ryngeal wall cancer } \\
\text { (T3NOMO), stage III }\end{array}$ & M & 51 & 66 & TXT 10 mg/m²/week & $\begin{array}{c}\text { ELPS (positive horizontal } \\
\text { margins) }\end{array}$ & 6 \\
\hline \multirow{2}{*}{$\begin{array}{l}\text { 6. Hypopharyn- } \\
\text { geal carcinoma at } \\
\text { the pyriform sinus } \\
\text { (T1N2bM0), stage IV }\end{array}$} & \multirow[t]{2}{*}{ M } & \multirow[t]{2}{*}{62} & \multirow[t]{2}{*}{66} & \multirow[t]{2}{*}{ TXT 10 mg/m²/week } & $\begin{array}{l}\text { ESD (esophagus), subtotal } \\
\text { esophagectomy, distal gas- } \\
\text { trectomy, }\end{array}$ & \multirow[t]{2}{*}{68} \\
\hline & & & & & Colon reconstruction & \\
\hline $\begin{array}{l}\text { 7. Nasopharyngeal } \\
\text { cancer } \\
\text { (unknown) }\end{array}$ & M & 78 & $\begin{array}{l}\text { Un- } \\
\text { known }\end{array}$ & Unknown & None & $\begin{array}{l}\text { Approximately } \\
>120\end{array}$ \\
\hline $\begin{array}{l}\text { 8. Superior oropha- } \\
\text { ryngeal wall cancer } \\
\text { (T2NOMO), stage II }\end{array}$ & M & 76 & 66 & TXT 10 mg/m²/week & $\begin{array}{l}\text { Soft palate resection, unilater- } \\
\text { al cervical dissection, forearm } \\
\text { flap reconstruction }\end{array}$ & 79 \\
\hline $\begin{array}{l}\text { 9. Posterior oropha- } \\
\text { ryngeal wall cancer } \\
\text { (T4NOMO), stage IV }\end{array}$ & M & 58 & 70 & $\begin{array}{c}\text { CDDP } 100 \mathrm{mg} / \mathrm{m}^{2} / \\
3 \text { week }\end{array}$ & None & 4 \\
\hline \multirow[t]{2}{*}{$\begin{array}{l}\text { 10. Maxillary cancer } \\
\text { (T3NOMO), stage III }\end{array}$} & \multirow[t]{2}{*}{ M } & \multirow[t]{2}{*}{69} & \multirow[t]{2}{*}{40} & $\begin{array}{l}\text { CBDCA } 75 \mathrm{mg} / \mathrm{m}^{2} \\
\text { (Day 1), 5FU } 250 \mathrm{mg} \\
\text { (Day } 3,5) 4 \text { courses }\end{array}$ & \multirow{2}{*}{$\begin{array}{l}\text { Total maxillectomy, forearm } \\
\text { flap reconstruction, subtotal } \\
\text { esophagectomy, gastric tube } \\
\text { reconstruction }\end{array}$} & \multirow[t]{2}{*}{200} \\
\hline & & & & $\begin{array}{l}\text { Intra-arterial injection } \\
\text { via the superficial } \\
\text { temporal artery }\end{array}$ & & \\
\hline
\end{tabular}

to swallow was provided to patients. Four months after discharge, a patient was readmitted to the Department of Esophageal Surgery because of hemor- rhaging from the pharynx. To identify the source of the hemorrhaging, esophagogastroduodenoscopy (EGD). This seems to be a series of Olympus video- 
Table II. A list of resected lesions. All margins were confirmed to be negative regardless of tumor site and extent of disease

\begin{tabular}{|c|c|c|c|c|c|c|c|c|c|}
\hline Site & T stage & $\begin{array}{c}\text { Macroscopic } \\
\text { pathological stage }\end{array}$ & $\begin{array}{l}\text { Invasion } \\
\text { depth }\end{array}$ & ly & $\mathrm{v}$ & $\mathrm{n}$ & VM & $\mathrm{HM}$ & $\mathrm{R}$ \\
\hline Lateral oropharyngeal wall & In situ & $0-I 1 b$ & EP & 0 & 0 & 0 & 0 & 0 & 0 \\
\hline Posterior oropharyngeal wall & In situ & $0-11 b$ & SEP & 1 & 0 & 0 & 0 & 0 & 0 \\
\hline Lateral oropharyngeal wall & In situ & $0-11 b$ & SEP & 0 & 0 & 0 & 0 & 0 & 0 \\
\hline Anterior oropharyngeal wall & In situ & $0-11 b$ & EP & 0 & 0 & 0 & 0 & 0 & 0 \\
\hline Arytenoid region of the hypopharynx & In situ & $0-11 b$ & EP & 0 & 0 & 0 & 0 & 0 & 0 \\
\hline Post-cricoid region of the hypopharynx & In situ & $0-11$ & SEP & 0 & 1 & 0 & 0 & 0 & 0 \\
\hline Posterior hypopharyngeal wall & In situ & $0-11 a$ & SEP & 0 & 0 & 0 & 0 & 0 & 0 \\
\hline Pyriform sinus of the hypopharynx & In situ & $0-11 b$ & EP & 0 & 0 & 0 & 0 & 0 & 0 \\
\hline Posterior hypopharyngeal wall & In situ & $0-1$ & MP & 2 & 2 & 1 & 0 & 0 & 0 \\
\hline Posterior oropharyngeal wall & In situ & $0-11 c$ & EP & 0 & 0 & 0 & 0 & 0 & 0 \\
\hline Posterior oropharyngeal wall & In situ & $0-11 c$ & EP & 0 & 0 & 0 & 0 & 0 & 0 \\
\hline Lateral oropharyngeal wall & In situ & $0-11 b$ & SEP & 0 & 0 & 0 & 0 & 0 & 0 \\
\hline Superior oropharyngeal wall & In situ & $0-I 1 b$ & EP & 0 & 0 & 0 & 0 & 0 & 0 \\
\hline Anterior oropharyngeal wall & In situ & $0-11 a$ & SEP & 0 & 0 & 0 & 0 & 0 & 0 \\
\hline
\end{tabular}

Macroscopic classification: 0-l: superficial and protruding type, more than $1 \mathrm{~mm}$ in height, 0-Ila: slightly elevated type, less than $1 \mathrm{~mm}$ in height, 0-IIb: flat type, 0-IIc: slightly depressed type, less than $0.5 \mathrm{~mm}$ in depth. Pathological classification: EP: carcinoma in situ, SEP: tumor invades subepithelial layer, MP: tumor invades muscularis propria (ly: lymphatic invasion, $v$ : venous invasion, $n$ : nerve invasion, VM: vertical margins, HM: horizontal margins, $R$ : overall results). Everything complies with the guidelines from the Japan Society for Head and Neck Cancer (6 $6^{\text {th }}$ Edition).

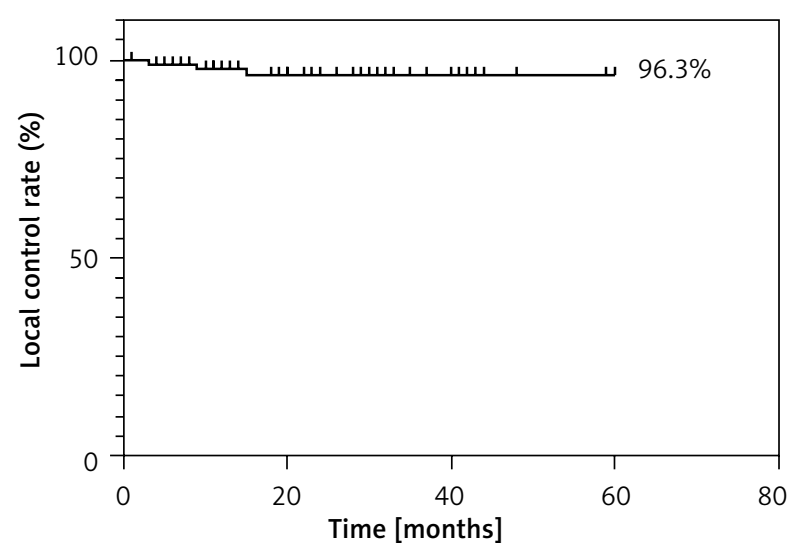

Figure 1. Five-year local control rate. Recurrence at the same site that was resected was not observed and outcomes were very good at $96.3 \%$

gastroscopes, not a technique, was performed twice, which revealed that the piriform sinus had decreased in size and, owing to scarring, had become very hard. However, bleeding was only observed while passing through the piriform sinus and the source of the hemorrhaging was unclear. The source

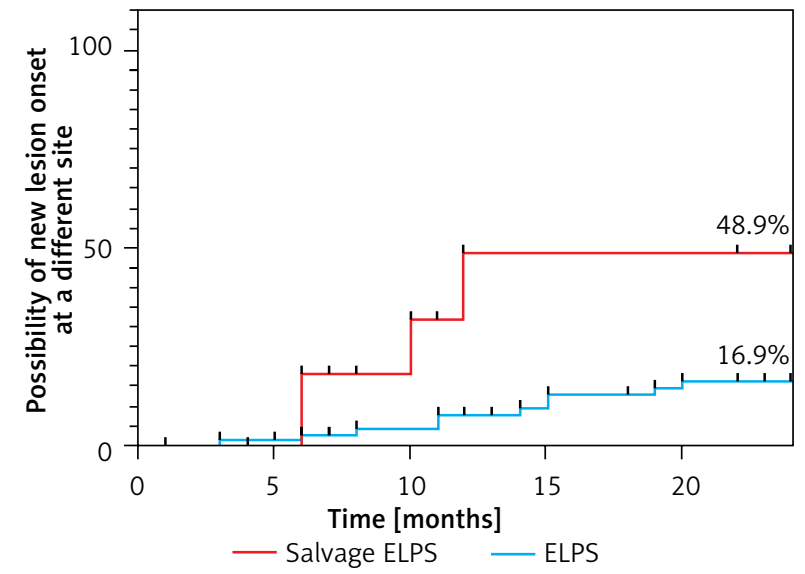

Figure 2. Postoperative incidence of head and neck cancer at different sites. The rate of onset of new lesions at different sites was $16.4 \%$ at 2 years for conventional ELPS; however, for salvage ELPS following chemoradiation therapy, the corresponding rate reached $48.9 \%$ (log-rank (Mantel-Cox) test $p=0.01$ ) 
of hemorrhaging could also not be identified on contrast-enhanced CT. Thereafter, the Department of Otorhinolaryngology was also consulted and an observation of the esophageal inlet could be performed; however, the source of the hemorrhaging could not be found. Nevertheless, at this stage, the edema in the arytenoid region, vocal cord paralysis, and pharyngeal pain had intensified. To find the cause, the site was expanded using Sato's curved laryngoscope under general anesthesia and arterial bleeding from the hypopharyngeal piriform sinus was observed; thus, angiography was performed by a radiologist. The source of the hemorrhaging was found to be a pseudoaneurysm in the common carotid artery and, upon stent placement by a neurosurgeon, the bleeding temporarily stopped (Photo 1). However, 2 months later, the patient died due to recurrent hemorrhaging. Prior to the recurrence of
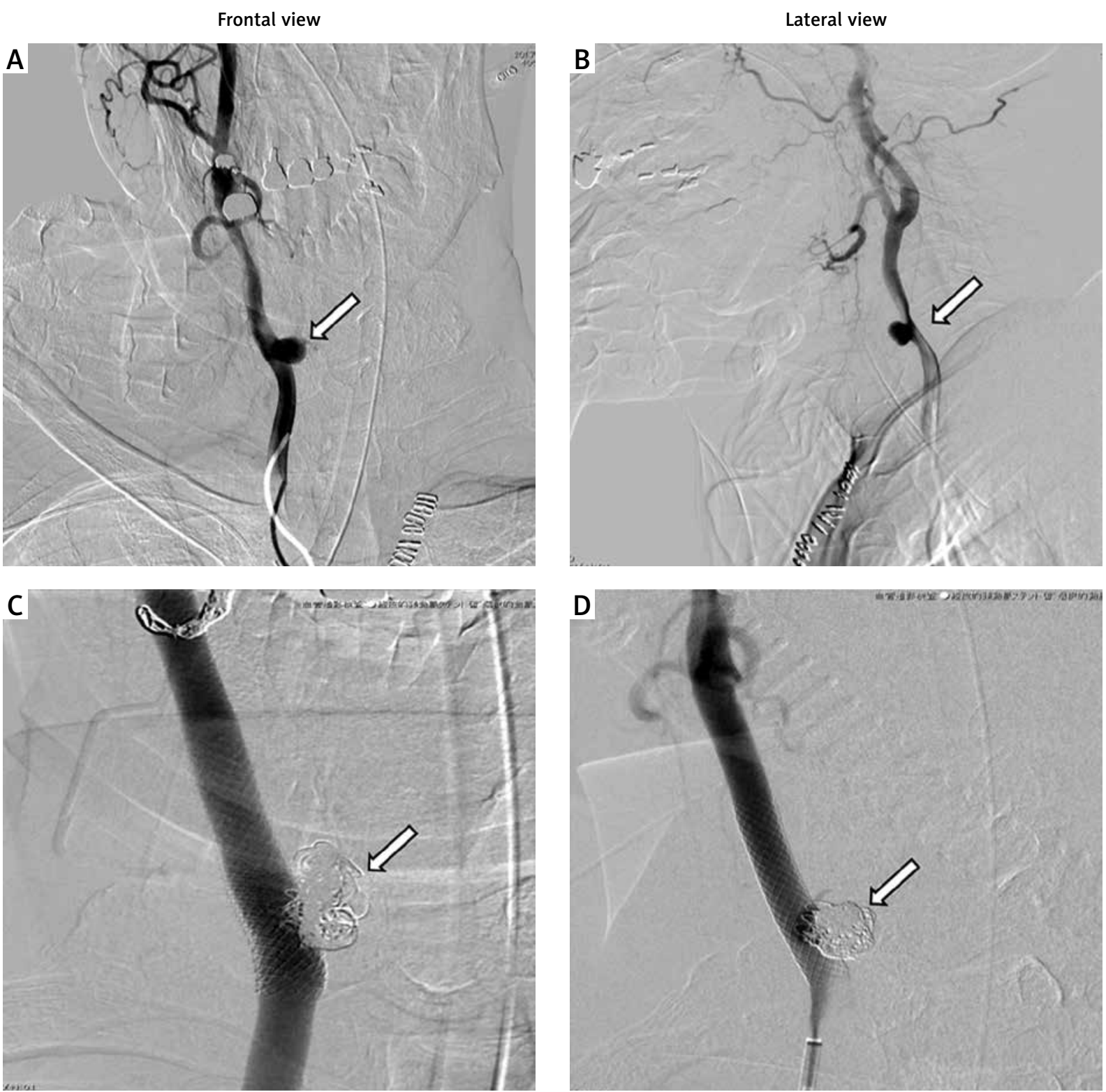

Photo 1. Pseudoaneurysm identified by angiography (arrow). A, B - A pseudoaneurysm is seen in the right common carotid artery. The site is consistent with the location of the piriform sinus of the right hypopharynx. C, D - Coil embolization and stent placement were performed by the Department of Neurosurgery. Blood flow is maintained in the common carotid artery and the site of pseudoaneurysm has been embolized 

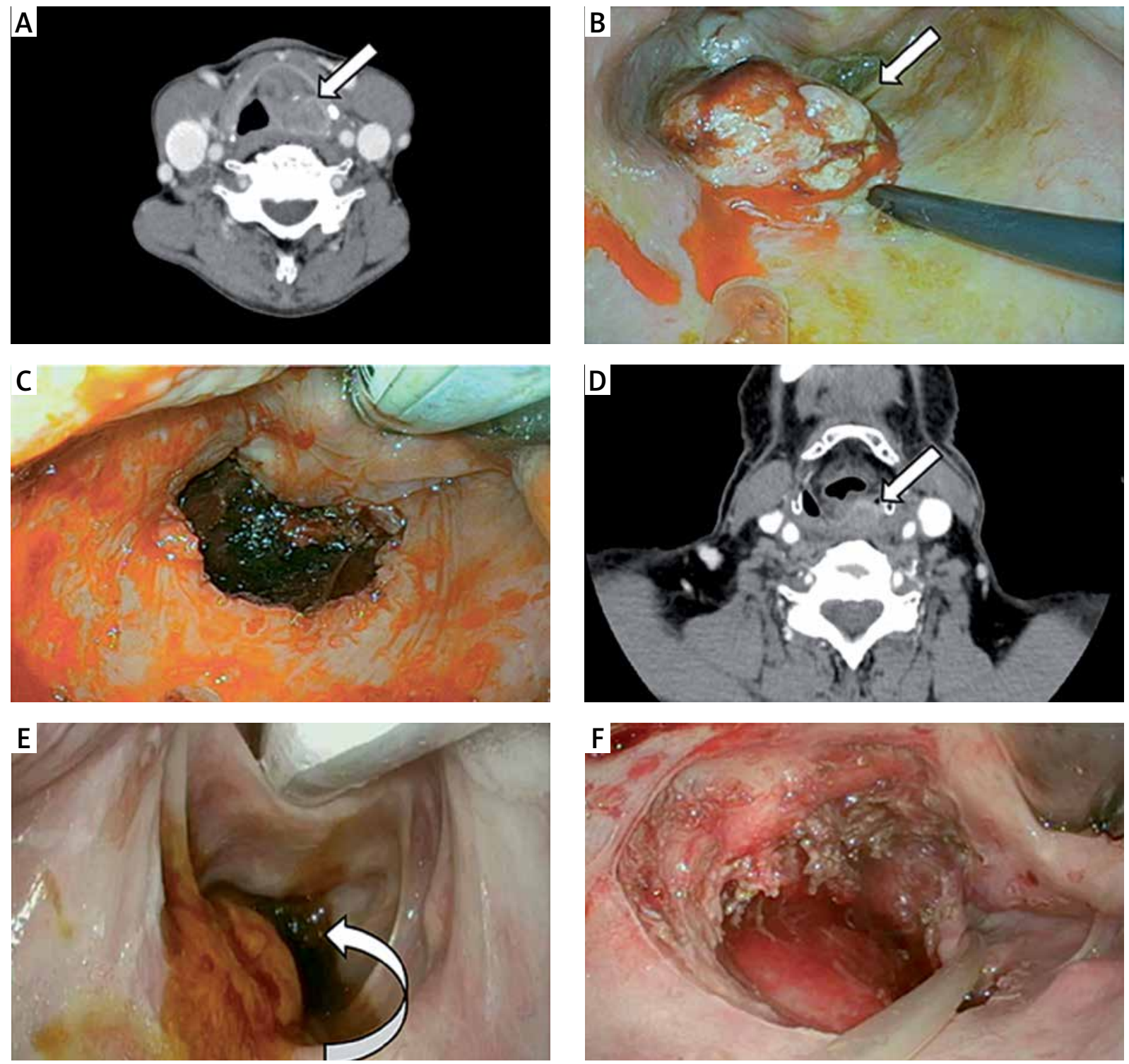

Photo 2. Comparison of cancer of the posterior oropharyngeal wall arising in similar sites (white arrow). A - CT of cancer of the posterior oropharyngeal wall in a fresh patient, $\mathbf{B}-$ a tumor is observed in the expected site upon exposing the larynx, C - after resection, D - CT of cancer of the posterior oropharyngeal wall following radiation therapy, $\mathrm{E}$ - upon exposing the larynx, the tumor is drawn in the direction of the cervical esophagus, $\mathbf{F}$ - after resection

hemorrhaging, salvage surgery through the reconstruction of a forearm flap was proposed; however, neither the patient nor the patient's family wished for further surgery or treatment. This patient had previously undergone total esophagectomy, subtotal gastrectomy, pancreaticoduodenectomy, and colon reconstruction, and was thus believed to have poor reserve capacity. Furthermore, according to the patient's family, the patient had been swallowing normal food with considerably strong swallowing pres- sure at home. Moreover, EGD was performed twice to identify the source of hemorrhaging, thereby adding mechanical stress. The cause of hemorrhaging was presumed to be the rupture of the aneurysm upon laryngeal expansion under general anesthesia due to strong swallowing pressure rupturing the mucosa and, since the patient had no reserve capacity for wound healing, infection spreading and resulting in the formation of a pseudoaneurysm, and further rupturing of the mucosa due to EGD. 


\section{Discussion}

ELPS contributes greatly to improving quality of life $(\mathrm{QOL})$ by enabling the avoidance of complications such as severe dysphagia and thirst caused by chemoradiation therapy, and loss of vocal function caused by surgery. Even if patients with a history of receiving chemoradiation therapy who, unfortunately, in some instances, develop head and neck cancer within the irradiation field, become candidates for ELPS, similar to fresh patients, this should not significantly impact the patient's QOL. However, in reality, ELPS following irradiation differs greatly compared with normal ELPS and involves high risks. First, because prior chemoradiation therapy and surgery can make pharyngolaryngeal deformation more severe and the tissues can be very hard, surgery is very difficult. Furthermore, the location of the tumor may differ when observed on an outpatient basis as opposed to expansion under general anesthesia (Photo 2). Moreover, the borders of the tumor are often unclear despite performing narrow band imaging and Lugol staining; therefore, it is very difficult to determine the extent of excision. With present endoscopic imaging and conventional methods, the accurate determination of the extent of excision, as with fresh patients, is considered difficult. Surgery should be discontinued to avoid complications if the extent of excision is large and the tumor cannot be visualized and exposed. In the present study, we obtained experience in a patient with extremely severe complications of a pseudoaneurysm rupture resulting in death. In Japan, there have been reports of recurring infection of the larynx with endoscopic submucosal dissection following irradiation leading to total laryngectomy and retropharyngeal and mediastinal abscess. Although there have also been previous reports of oral tumor resection following irradiation [10-16], many of which indicate that the procedure was successful, there are few reports describing complications and risks. However, Tomifuji et al. performed transoral videolaryngoscopic surgery and reported that swallowing function significantly deteriorated, and the epithelization of the wound took over 3 months, leading to infection and necrosis [17]. We had the same impression; thus, we frequently made postoperative endoscopic observations and, as required, performed contrast-enhanced $\mathrm{CT}$, and took an extremely careful approach such as not rushing oral intake. Despite these mea- sures, hemorrhaging from a pseudoaneurysm could not be prevented during the resection of the piriform sinus. The piriform sinus is dangerous and should probably be excluded as a site indicated for salvage ELPS. For patients with a history of receiving irradiation, even transoral robotic surgery [18], which will be introduced in Japan in the future, may possibly carry the same risks.

\section{Conclusions}

Salvage ELPS following chemoradiation therapy is technically challenging and, even if local control is achieved, there is a very high probability that cancer will develop at a different site. It is always important to perform follow-up to monitor the appearance of new cancers. Furthermore, depending on the surgical site and extent of excision, it is possible that severe complications will develop and, once complications arise, become very serious. At this stage, considerably narrowing those indicated for surgery and obtaining full informed consent are considered important.

\section{Conflict of interest}

The authors declare no conflict of interest.

\section{References}

1. Tateya I, Morita S, Muto M, et al. Magnifying endoscope with $\mathrm{NBI}$ to predict the depth of invasion in laryngeal-pharyngeal cancer. Laryngoscope 2015; 125: 1124-9.

2. Muto M, Nakane M, Katada C, et al. Squamous cell carcinoma in site at oropharyngeal and hypopharyngeal mucosal site. Cancer 2004; 101: 1375-81.

3. Watanabe A, Tsujie H, Taniguchi M, et al. Laryngoscopic detection of pharyngeal carcinoma in situ with narrow band imaging. Laryngoscope 2006; 116: 650-4

4. Tateya I, Akihiro S, Yasuo S, et al. Transoral surgery for laryngo-pharyngeal cancer-The paradigm shift of the head and cancer treatment. Auris Nasus Larynx 2016; 43: 21-32.

5. Sato Y, Omori Y, Tagawa W. Surgical treatment for hypopharyngeal superficial cancer: endoscopic laryngo-pharyngeal surgery. Nihon Jibiinkoka Gakkai Kaiho 2006; 109: 581-6.

6. Tateya I, Muto M, Morita S, et al. Endoscopic laryngo-pharyngeal surgery for superficial laryngo-pharyngeal cancer. Surg Endosc 2015; 30: 323-9.

7. Nakayama M, Katada C, Mikami T, et al. A clinical study of transoral pharyngectomies to treat superficial hypopharyngeal cancers. Jpn J Clin Oncol 2013; 43: 782-7.

8. Kawasaki Y, Omori Y, Saito H, et al. An investigation on endoscopic laryngopharyngeal surgery and related outcomes. Videosurgery Miniinv 2018; 13: 394-400. 
9. Sakai A, Okami K, Sugimoto R et al. A new technique to expose the hypopharyngeal space: the modified Killian's method. Auris Nasus Larynx 2014; 41: 207-10.

10. Steiner W, Vogt P, Ambrosch P, et al. Transoral carbon dioxide laser microsurgery for recurrent glottic carcinoma after radiotherapy. Head Neck 2004; 26: 477-84.

11. Roedel RM, Matthias C, Wolff HA, et al. Transoral laser microsurgery for recurrence after primary radio-therapy of early glottic cancer. Auris Nasus Larynx 2010; 37: 474-81.

12. Han YJ, Lee HS, Kim SW, et al. Transoral laser microsurgery for early glottic cancer after radiation therapy: clinical feasibility and limitations. Ann Otol Rhinol Laryngol 2012; 121: 375-82.

13. Huang J, Yu Z, Fang J, et al. Salvage transoral laser microsurgery for recurrent glottic carcinoma after primary laser treatment. Acta Otolaryngol 2013; 133: 531-7.

14. Del Bon F, Piazza C, Mangili S, et al. Transoral laser surgery for recurrent glottic cancer after radiotherapy: oncologic and functional outcomes. Acta Otorhinolaryngol Ital 2012; 32: 229-37.

15. Reynolds LF, Rigby MH, Trites J, et al. Outcomes of transoral la ser microsurgery for recurrent head and neck cancer. J Laryngol Otol 2013; 127: 982-6.

16. White H, Ford S, Bush B, et al. Salvage surgery for recurrent cancer of the oropharynx: comparing TORS with standard open surgical approach. JAMA Otolaryngol Head Neck Surg 2013; 139: 773-8.

17. Tomifuji M, Araki K, Yamashita T, et al. Salvage transoral videolaryngoscopic surgery for radiorecurrent hypopharyngeal and supraglottic cancer. Auris Nasus Larynx 2017; 44: 464-71.

18. Weinstein GS, O'Malley Jr BW, et al. Transoral robotic surgery: does the ends justify the means? Curr Opin Otolaryngol Head and Neck Surg 2009; 17: 126-31.

Received: 20.03.2020, accepted: 25.03.2020. 